\title{
Nocardia cyriacigeogica from Bovine Mastitis Induced In vitro Apoptosis of Bovine Mammary Epithelial Cells via Activation of Mitochondrial-Caspase Pathway
}

\author{
Wei Chen ${ }^{1}$, Yongxia Liu ${ }^{2}$, Limei Zhang ${ }^{1}$, Xiaolong Gu ${ }^{1}$, Gang Liu ${ }^{1}$, Muhammad Shahid ${ }^{1}$, \\ Jian Gao ${ }^{1}$, Tariq Ali ${ }^{1}$ and Bo Han ${ }^{1 *}$ \\ ${ }^{1}$ Department of Veterinary Clinics, College of Veterinary Medicine, China Agricultural University, Beijing, China, ${ }^{2}$ Department \\ of Veterinary Clinics, College of Veterinary Medicine, Shandong Agricultural University, Tai'an, China
}

OPEN ACCESS

Edited by:

Yongqun "Oliver" $\mathrm{He}$ University of Michigan Health System, United States

Reviewed by:

Agnès Wiedemann Institut National de la Recherche Agronomique (INRA), France Xiaohui Zhou, University of Connecticut, United States

*Correspondence: Bo Han

hanbo@cau.edu.cn

Received: 15 December 2016 Accepted: 03 May 2017 Published: 18 May 2017

Citation:

Chen W, Liu Y, Zhang L, Gu X, Liu G, Shahid M, Gao J, Ali T and Han B (2017) Nocardia cyriacigeogica from Bovine Mastitis Induced In vitro Apoptosis of Bovine Mammary Epithelial Cells via Activation of Mitochondrial-Caspase Pathway. Front. Cell. Infect. Microbiol. 7:194. doi: 10.3389/fcimb.2017.00194
Nocardia is one of the causing agents of bovine mastitis and increasing prevalence of nocardial mastitis in shape of serious outbreaks has been reported from many countries. However, the mechanisms by which this pathogen damages the bovine mammary epithelial cells (bMECs) is not yet studied. Therefore, this study was designed with the aim to evaluate the apoptotic effects elicited by Nocardia and to investigate the pathway by which the Nocardia induce apoptosis in bMECs. Clinical Nocardia cyriacigeorgica strain from bovine mastitis was used to infect the bMECs for different time intervals, viz. 1, 3, 6, 12 , and $18 \mathrm{~h}$, and then the induced effects on bMECs were studied using adhesion and invasion assays, release of lactate dehydrogenase ( $\mathrm{LDH})$, apoptosis analysis by annexin $\mathrm{V}$ and propidium iodide (PI) double staining, morphological, and ultrastructural observations under scanning electron microscope (SEM) and transmission electron microscope (TEM), mitochondrial transmembrane potential $(\Delta \Psi \mathrm{m})$ assay using flow cytometry, and the protein quantification of mitochondrial cytochrome $c$ and caspase- 9 and caspase-3 by western blotting. The results of this study showed that $N$. cyriacigeorgica possessed the abilities of adhesion and invasion to bMECs. N. cyriacigeorgica was found to collapse mitochondrial transmembrane potential, significantly $(p<0.05)$ release mitochondrial cytochrome $\mathrm{c}$ and ultimately induce cell apoptosis. Additionally, it promoted casepase- 9 $(p<0.01)$ and casepase-3 $(p<0.05)$ levels, significantly $(p<0.01)$ increased the release of $\mathrm{LDH}$ and promoted DNA fragmentation which further confirmed the apoptosis. Furthermore, N. cyriacigeorgica induced apoptosis/necrosis manifested specific ultrastructure features under TEM, such as swollen endoplasmic reticulum, cristae degeneration, and swelling of mitochondria, vesicle formation on the cell surface, rupturing of cell membrane and nuclear membrane, clumping, fragmentation, and margination of chromatin. The present study is the first comprehensive insight into patho-morphological ultrastructural features of apoptosis/necrosis induced by N. cyriacigeorgica, which concluded that the clinical N. cyriacigeorgica induced apoptotic changes in the bMECs through mitochondrial-caspase dependent apoptotic pathway.

Keywords: bovine mastitis, Nocardia cyriacigeorgica, bMECs, ultrastructural feature, mitochondria-dependent apoptotic pathway 


\section{INTRODUCTION}

Nocardia species are gram-positive, aerobic, saprophytic, and widespread environmental actinomycetes, which have been reported as an opportunistic intracellular pathogen of human and animals (Sullivan and Chapman, 2010; Conville and Witebsky, 2011). Nocardia can cause localized or systemic nocardiosis with purulency or granulomas (Holland, 2010), which is probably transmitted by inhalation, ingestion or traumatic implantation, and can be disseminated through lymph and blood circulation (Ambrosioni et al., 2010). The most important species causing nocardiosis include $N$. cyriacigeorgica, N. asteroides, N. brasiliensis, N. farcinica, and N. nova (Ribeiro et al., 2008; Liu et al., 2011; Condas et al., 2013; Brown-Elliott et al., 2015; Hashemi-Shahraki et al., 2015). In human beings, the common manifestations of nocardiosis are pulmonary nocardiosis, central nervous system (CNS) nocardiosis, extrapulmonary nocardiosis, cutaneous, subcutaneous or lymphocutaneous nocardiosis, and nocardial bacteremia (Ambrosioni et al., 2010; Al Akhrass et al., 2011; Wilson, 2012). Whereas, in cattle, it is associated with farcy, abortion, pulmonary, and systemic nocardiosis (Beaman and Sugar, 1983; Bawa et al., 2010; Hamid, 2012). Nocardial bovine mastitis is the most important manifestation of nocardiosis and it has been reported from many countries (Dohoo, 1989; Hamid et al., 1998; Cook and Holliman, 2004; Brown et al., 2007; Pisoni et al., 2008; Ribeiro et al., 2008; Condas et al., 2013). Nocardial mastitis is characterized by the suppurative or granulomatous inflammation of the mammary gland followed an acute or chronic course (Bättig et al., 1989; Pisoni et al., 2008; Ribeiro et al., 2008). Moreover, its huge economic losses are mostly due to decrease milk production and culling of dairy cows (Cook and Holliman, 2004; Condas et al., 2013).

Bacterial adhesion and invasion are considered as important pathogenetic and virulence factors in the infection processes (Dego et al., 2002). Several in vivo and in vitro experiments demonstrated that Nocardia possessed the abilities to adhere to and invade into various types of cells, inducing cellular and tissue damages (Beaman and Beaman, 1998; Chapman et al., 2003; Beaman and Tam, 2008; Kohbata et al., 2009). When Nocardia attached to and rapidly penetrated through capillary endothelial cells (Beaman and Ogata, 1993), then entered the brain parenchyma, eliciting Lewy body inclusion in brain and Parkinson's symptoms in experimental animals (Chapman et al., 2003; Beaman and Tam, 2008). A previous study reported that Nocardia infection may induce macrophages and dendritic cells to differentiate into foamy cells (Meester et al., 2014). Furthermore, the invasion of Nocardia can even lead to the prevention of phagosome-lysosome fusion), inhibition of proteasome activity (Barry and Beaman, 2007), resistance to oxidative killing, blockage of phagosomal acidification, and alteration of lysosomal enzyme activity in macrophages (Beaman and Beaman, 1994). Staphylococcus aureus adhesion and invasion to bovine mammary epithelial cells (bMECs) has been proven to be the key events in the pathogenesis of bovine mastitis and the infected cells exhibited apoptotic morphology (Bayles et al., 1998; Dego et al., 2002); but for Nocardia, the adhesion and invasion ability to bMECs and the cell death effects are still unclear.
Cell death, the ultimate consequence of injury in host cells infection mainly includes apoptosis and necrosis. Necrosis is characterized by loss of cell membrane integrity, release of cellular contents and motivating inflammatory reaction; whereas, apoptosis is generally developed with cell membrane integrity, internucleosomal DNA fragmentation, formation of apoptotic bodies, no inflammatory reaction, and mediated through the intrinsic and extrinsic apoptosis pathway (Lamkanfi and Dixit, 2010). The extrinsic apoptosis pathways involve death receptors and caspase- 8 signaling; whereas the intrinsic apoptotic pathway mainly targets the mitochondria (Lamkanfi and Dixit, 2010; Galluzzi et al., 2012).

In many bacterial pathogens, mitochondria-dependent apoptotic pathways have been well-recognized as a major pathogenic strategy (Ashida et al., 2011). During the process, apoptotic factors opens the mitochondrial permeability transition pore that ultimately result in loss of membrane potential and activation of cytochrome c (Yang et al., 2015; $\mathrm{Xu}$ et al., 2016). Then cytochrome c binds to apoptotic protease-activating factor I (Apaf-I) and tempts oligomerization. Consequently, apoptosome complex form by assembling of Apaf-1 oligomers with procaspase-9. Caspase-9 subsequently triggers apoptosis by caspase-3 activation (Elmore, 2007; Lamkanfi and Dixit, 2010). However, the specific mechanism through which capsase-9 activation triggers apoptosis in response to $N$. cyriacigeorgica in bMECs is unclear. Nocardia was shown to induce apoptotic death in dopaminergic cells, PC12 cells and HeLa cells; meanwhile, disruption of the mitochondrial membrane potential and caspase activation were involved in the apoptosis of HeLa cells (Barry and Beaman, 2007). However, the cell death effect of Nocardia on bMECs and the specific mechanisms involved in response to nocardial infection remain unknown.

Although, most of studies on Nocardia infections in various cells and laboratory animals were performed to demonstrate the pathogenicity and pathogenic mechanisms in central nervous system, respiratory system, and skin or cutaneous tissues (Barry and Beaman, 2007; Beaman and Tam, 2008; Meester et al., 2014; Lira et al., 2016). Nevertheless, there are rare studies focused on pathogenicity and mechanism underlying bovine mastitis caused by $N$. cyriacigeorgica. Therefore, the current study was designed with hypothesis that the Nocardia could adhere to and invade into bMECs, inducing apoptotic and necrotic cell death; in addition, Nocardia may regulate the cell apoptosis via mitochondrial-caspase pathway.

\section{MATERIALS AND METHODS}

\section{Cell Culture}

The bMECs line MAC-T was used in this study which was purchased from Shanghai Jingma Biological Technology Co., Ltd. China. Cells were cultured in DMEM/F-12 (HyClone, USA) supplemented with $10 \%$ heat-inactivated Gibco ${ }^{\circledR}$ Fetal Bovine Serum (FBS; HyClone, USA), $100 \mathrm{U} / \mathrm{mL}$ penicillin and 100 $\mu \mathrm{g} / \mathrm{mL}$ streptomycin at $37^{\circ} \mathrm{C}$ with $5 \% \mathrm{CO}_{2}$. Cells for adhesion and invasion assay were cultured in DMEM/F12 medium without antibiotics and while for other assays bMECs were cultured in DMEM/F12 medium with 4\% FBS without antibiotics. 


\section{Bacterial Culture}

$N$. cyriacigeorgica isolated previously from bovine mastitis was activated from frozen stocks by culture on tryptose soya agar (Difco $^{\mathrm{TM}}$, Becton Dickison, Sparks, MD USA) supplemented with $5 \%$ defibrinated sheep blood and incubated at $37^{\circ} \mathrm{C}$ for $72 \mathrm{~h}$, then sub-cultured in $7 \mathrm{H} 9$ broth to mid-log phase for the following experiments.

\section{Adhesion Assay}

Adhesion assay of clinical $N$. cyriacigeorgica to bMECs was performed according to previously described protocols (Pöhlmann-Dietze et al., 2000; Pereyra et al., 2016), with slight modifications as bMECs were infected with $N$. cyriacigeorgica at a multiplicity of infection (MOI, ratio of $N$. cyriacigeorgica to cells) of $50: 1$ for $10 \mathrm{~min}, 1,2$, and $3 \mathrm{~h}$ at $37^{\circ} \mathrm{C}$ with $5 \%$ $\mathrm{CO}_{2}$. After incubation, the supernatants of infected cells were removed and cells were washed three times with phosphate buffer saline (PBS, $\mathrm{pH}$ 7.4) to remove non-adherent bacteria. Subsequently, cells were lysed by $1 \mathrm{~mL}$ PBS and $1 \mathrm{~mL} 1 \%$ Triton X-100 $(0.5 \% \mathrm{v} / \mathrm{v})$ to release adherent Nocardia. In control groups, both Nocardia suspensions $(1 \mathrm{~mL})$ and the cells were also treated with $1 \mathrm{~mL}$ Triton X-100. Finally, cell lysates and treated Nocardia supernatants were 10-folds serially diluted, plated onto sheep blood agar plates and incubated at $37^{\circ} \mathrm{C}$ for $48 \mathrm{~h}$ for enumeration of colony forming units (CFU). Adhesion rate of total Nocardia was expressed as:
Invasion rate of total Nocardia was expressed as:

Invasion rate of total Nocardia $=$

$$
\begin{aligned}
& \text { Adhesion rate of total Nocardia } \times \\
& \text { Invasion rate of adhered Nocardia }
\end{aligned}
$$

The invasion assay was repeated four times and each experiment was performed in quadruplicate.

\section{Lactate Dehydrogenase (LDH) Release Assay}

$\mathrm{LDH}$, an enzyme, normally present in the cytoplasm and could release into the cell culture medium through damaged cell membrane after bacterial infection (Loeffler et al., 2004; Viguier et al., 2009). LDH release assay can be used to evaluate cytopathic effect of $N$. cyriacigeogica on bMECs. Cells were infected with $N$. cyriacigeorgica at a MOI of 5:1 for $1,3,6,12$, and $18 \mathrm{~h}$ at $37^{\circ} \mathrm{C}$ with $5 \% \mathrm{CO}_{2}$. In addition, Nocardia suspensions in DMEM/F12 with 4\% FBS and noninfected cells incubated for the same time were used as control. After incubation, the supernatants were collected and centrifuged at $18,000 \mathrm{~g}$ for $15 \mathrm{~min}$. The supernatants were collected again for measurement of LDH release by cytotoxicity LDH Assay Kit-WST ${ }^{\circledR}$ (Dojingdo Laboratories, Kumamoto, Japan). The absorbance at $490 \mathrm{~nm}$ was measured by a microplate reader.

$$
\text { Adhesion rate of total Nocardia }=\frac{\text { Lysate of infected cells }(\mathrm{CFU} / \mathrm{mL})}{\text { Lysate of Nocardia supernatant and infected cells }(\mathrm{CFU} / \mathrm{mL})} \times 100
$$

The adhesion assay was repeated four times and each experiment was performed in quadruplicate.

\section{Invasion Assay}

In our previous study, we tested several dilutions of amikacin (25, $50,75$, and $100 \mu \mathrm{g} / \mathrm{mL})$ with high concentration of Nocardia $(1 \times$ $\left.10^{7} \mathrm{CFU} / \mathrm{mL}\right)$ and with different incubation time (1, 2, and $\left.3 \mathrm{~h}\right)$. As a result, we found that $50 \mu \mathrm{g} / \mathrm{mL}$ of amikacin was enough to kill all Nocardia within $2 \mathrm{~h}$; thus, this concentration of amikacin and incubation time was used for the following invasion assay. Invasion assay of $N$. cyriacigeorgica was performed according to the previous method with minor modifications (Beaman and Beaman, 1998; Pereyra et al., 2016). The bMECs were infected with $N$. cyriacigeorgica at a MOI of 50:1 for $10 \mathrm{~min}, 1,2$, and $3 \mathrm{~h}$. Following incubation, cells were washed three times with PBS and treated with amikacin $(50 \mu \mathrm{g} / \mathrm{mL})$ for $2 \mathrm{~h}$ to kill extracellular Nocardia. The infected cells without amikacin treatment were used as control group. Then, cells were washed three times with PBS to remove non-adherent bacteria, further lysed with $0.5 \%$ Triton X-100 (v/v). Finally, cell lysates were 10folds serially diluted for CFU determination. Invasion rate of adhered Nocardia was expressed as:

\section{DNA Ladder Analysis}

As a characteristic feature for apoptotic cell death, DNA ladder was applied for the verification of cell apoptosis. The bMECs were infected with $N$. cyriacigeorgica in the same manner as described above. Moreover, cells without Nocardia treatment were used as control. Fragmented DNA was collected from cells according to the manufacturer's instructions of the DNA Ladder Extraction Kit (Beyotime, China). Moreover, this kit was also used to extract the DNA of $N$. cyriacigeorgica to determine the interference effect of $N$. cyriacigeorgica DNA. Finally, the DNA samples were electrophoresed on a $1 \%$ agarose gel, stained with ethidium bromide, and photographed by gel documentation system (Alpha ${ }^{\circledR}$ Imager EC, SAN LEADRO, USA).

\section{Apoptosis/Necrosis Analysis by Annexin V/Propidium lodide (PI) Double Staining}

Cell death was detected by the FITC Annexin V Apoptosis Detection Kit I (BD, USA) according to the manufacturer's instructions. $N$. cyriacigeorgica were incubated with bMECs at a MOI of $5: 1$ for $1,3,6,12$, and $18 \mathrm{~h}$ at $37^{\circ} \mathrm{C}$ with $5 \% \mathrm{CO}_{2}$. Cells without Nocardia treatment were used as the control groups.

$$
\text { Invasion rate of adhered Nocardia }=\frac{\text { Lysate of infected cells with amikacin treatment }(\mathrm{CFU} / \mathrm{mL})}{\text { Lysate of infected cells without amikacin treatment }(\mathrm{CFU} / \mathrm{mL})} \times 100
$$


After incubation, cells were harvested, washed twice with cold PBS and re-suspended in binding buffer at a concentration of 1 $\times 10^{6}$ cells $/ \mathrm{mL}$, then $100 \mu \mathrm{L}$ of the cell suspension was stained by $5 \mu \mathrm{L}$ FITC Annexin V and $5 \mu \mathrm{L}$ PI. Following incubation for 15 min at room temperature, the samples were analyzed by the BD FacsCalibur flow cytometer (New Jersey, USA) within $1 \mathrm{~h}$.

\section{Scanning Electron Microscopy (SEM) and Transmission Electron Microscopy (TEM)}

The bMECs adhered on coverslips were washed three times with cold PBS and fixed with 2.5\% glutaraldehyde at $4^{\circ} \mathrm{C}$ for $1.5 \mathrm{~h}$ After washing, cells were dehydrated through a graded series of ethanol $(30,50,70,80,90,100$, and $100 \%$ ethanol) for $15 \mathrm{~min}$ in each at room temperature. Subsequently, cells were immersed into tert-butyl alcohol for $30 \mathrm{~min}$. After lyophilization and gold coating, these cell samples were observed on a scanning electron microscope (Hitachi S-3000N, Japan).

For TEM, cells were harvested and the pretreatment of the cells before dehydration was similar to that for SEM. After dehydration by graded ethanol and acetone (three changes, for 10 min each), cells were sequentially embedded in epoxy resinacetone mixtures $(2: 1)$ for $2 \mathrm{~h}$ and in pure resin overnight at $37^{\circ} \mathrm{C}$. When the resin had polymerized, ultra-thin sections were cut by an ultramicrotome (Leica EM, Germany), stained with $1 \%$ uranyl acetate followed by lead citrate and viewed on a transmission electron microscope (Hitachi H-7650, Japan).

\section{Mitochondrial Transmembrane Potential $(\Delta \Psi \mathrm{M})$ Assay}

The bMECs were infected with $N$. cyriacigeorgica at a MOI of 5:1 for $1,3,6,12$, and $18 \mathrm{~h}$ at $37^{\circ} \mathrm{C}$ with $5 \% \mathrm{CO}_{2}$. Cells were collected for mitochondrial damage detection according the changes of $\Delta \Psi \mathrm{m}$. The $\Delta \Psi \mathrm{m}$ was measured using a mitochondrial membrane potential assay kit with JC-1 (Beyotime, China) by flow cytometry. JC-1 was a dual-emission potential-sensitive probe and formed red-fluorescent aggregates in the mitochondria of the cells with higher potentials. But membrane potential collapse could result in the failure to red JC-1 in the mitochondria and the dye return to green-fluorescent monomer.

\section{Western Blot Analysis}

The bMECs were infected with $N$. cyriacigeorgica at a MOI of $5: 1$ for $1,3,6,12$, and $18 \mathrm{~h}$ at $37^{\circ} \mathrm{C}$ with $5 \% \mathrm{CO}_{2}$. Total proteins and cytoplasmic proteins without mitochondrion were respectively extracted from nocardial infected cells with RIPA lysis buffer (Beyotime, China) and Cell Mitochondria Isolation Kit (Beyotime, China). The protein concentrations were detected by the BCA method. Equivalent proteins from each sample were separated by SDS-PAGE gel, and then transferred onto PVDF membranes. Subsequently, the membranes were blocked in 5\% BSA and incubated with the primary antibody for Cytochrome C (1:200, Santa, USA), caspase- 9 (1:500, Santa, USA), caspase3 (1:100, Santa, USA), and tubulin (1:1,000, Cell Signaling Technology, USA) overnight at $4{ }^{\circ} \mathrm{C}$ followed by incubation with HRP-conjugated secondary antibody $(1: 5,000)$ for $1 \mathrm{~h}$ at room temperature. Finally, the bands were visualized using a BeyoECL Plus ECL Kit (Beyotime, China). Densitometric analysis of the bands was quantified using Image $J$ and these results were normalized using $\beta$-actin.

\section{Apoptosis Analysis in Parallel with the Growth of Intracellular N. cyriacigeorgica}

This experiment was carried out to evaluate the apoptosis and intracellular growth of Nocardia by killing the extracellular bacteria. The bMECs were infected with $N$. cyriacigeorgica at a MOI of 5:1 in DMEM/F12 for $2 \mathrm{~h}$. Following co-cultures, cells were washed with PBS and treated with amikacin $(50 \mu \mathrm{g} / \mathrm{mL}$ in DMEM/F12) for $2 \mathrm{~h}$ to kill extracellular Nocardia. Then, cells were washed three times with PBS and cultured in DMEM/F12 medium with $4 \%$ FBS for $0 \mathrm{~h}$ (control group), 1, 3, 6, 12, and $18 \mathrm{~h}$ at $37^{\circ} \mathrm{C}$ with $5 \% \mathrm{CO}_{2}$ for the following steps: (i) for cell apoptotic analysis, cells were collected, after incubation, for apoptotic analysis by the FITC Annexin V Apoptosis Detection Kit I (BD, USA) as previously described; (ii) for total bacterial counting, the medium $(1 \mathrm{~mL})$ with infected bMECs was treated with $1 \mathrm{~mL} 1 \%$ Triton X-100 (v/v) for the CFU enumeration of total Nocardia. Simultaneously, the parallel infected bMECs were washed three times with PBS, further lysed with Triton X100 and 10-folds serially diluted for CFU determination of the intracellular Nocardia. The number of Nocardia was expressed as $\log _{10}$ CFU/Well. The bacterial counting was repeated four times and each experiment was performed in quadruplicate; (iii) for observation of bacteria Gram staining was carried out. After washing with PBS, cells adhered on coverslips were fixed with $4 \%$ paraformaldehyde for $20 \mathrm{~min}$ and then permeabilized with $0.2 \%$ Triton X-100 (v/v) for $10 \mathrm{~min}$ at room temperature. Finally, cells were washed, stained by Gram staining and observed under light microscope (Olympus, Japan).

\section{Data Interpretation}

Each experiment was repeated at least three times and the data were expressed as mean \pm standard deviation $(S D)$. Statistical differences between groups were analyzed by One-way ANOVA followed by the Duncan and LSD multiple tests using SPSS 20.0 (SPSS, Inc., Chicago, IL, USA). $P$-value $<0.05$ was regarded as statistically significant.

\section{RESULTS}

\section{Adhesion and Invasion Assay}

The preliminary quantitative study is shown in Table 1. The adhesion rate of total $N$. cyriacigeorgica increased from 4.5 to $42.8 \%$ within $3 \mathrm{~h}$ and this increase was time-dependent. Whereas, the invasion rate of total Nocardia also showed a time-dependent increase from 3.3 to $33.35 \%$ within $3 \mathrm{~h}$. On the other hand, the invasion rate of adhered bacteria was persistent at a range of 64.4 to $77.9 \%$ within $3 \mathrm{~h}$, indicating that more than $60 \%$ of the adhered Nocardia can invade into cells. Remarkably, these data showed the rapid adhesive and invasive capabilities of $N$. cyriacigeorgica with bMECs (Table 1).

\section{LDH Release Assay}

As shown in Figure 1, there was release of $\mathrm{LDH}$ at 1, 3, and $6 \mathrm{~h}$ post-infection, however at 12 and $18 \mathrm{~h}$ post-infection there was a 
TABLE 1 | Adhesion and invasion rate of $N$. cyriacigeorgica to bMECs.

\begin{tabular}{lcccc}
\hline Item & \multicolumn{4}{c}{ Rate (\%) } \\
\cline { 2 - 5 } & $\mathbf{1 0} \mathbf{~} \mathbf{~ i n}$ & $\mathbf{1 ~ h}$ & $\mathbf{2 ~ h}$ & $\mathbf{3 ~ h}$ \\
\hline $\begin{array}{l}\text { Adhesion rate of total } \\
\text { Nocardia }\end{array}$ & $4.5 \pm 0.7$ & $22.0 \pm 2.6$ & $39.8 \pm 2.4$ & $42.8 \pm 1.8$ \\
$\begin{array}{l}\text { Invasion rate of } \\
\text { adhered Nocardia }\end{array}$ & $73.6 \pm 8.0$ & $64.4 \pm 8.4$ & $70.5 \pm 8.5$ & $77.9 \pm 7.9$ \\
$\begin{array}{l}\text { Invasion rate of total } \\
\text { Nocardia }\end{array}$ & $3.4 \pm 0.8$ & $14.3 \pm 3.0$ & $28.2 \pm 4.9$ & $33.4 \pm 4.1$ \\
\end{tabular}

Invasion rate of total Nocardia $=$ Adhesion rate of total Nocardia $\times$ Invasion rate of adhered Nocardia.

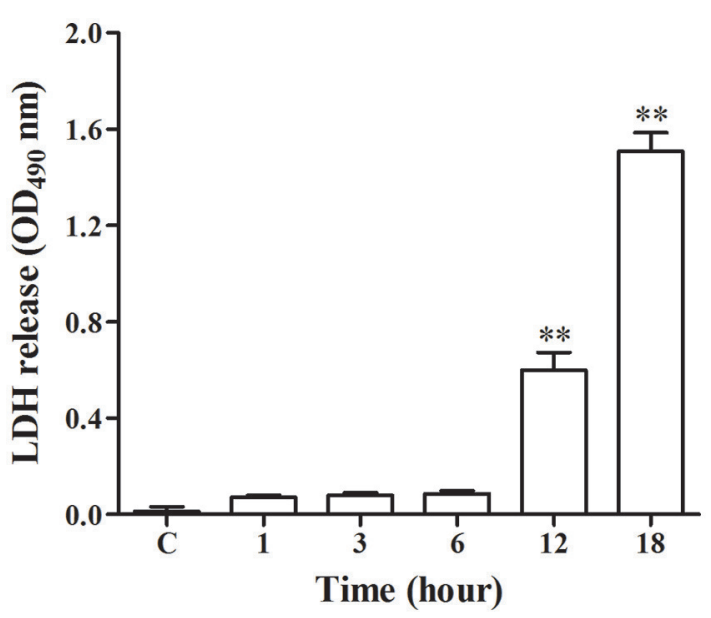

FIGURE 1 | Lactate dehydrogenase (LDH) release assay in the medium. The LDH release assay was repeated three times and each experiment was performed in triplicate. Results were presented as Mean $\pm \mathrm{SD}$. ${ }^{\star \star} P<0.01$ as compared to the control group.

significant increase $(p<0.01)$ of LDH as compared with control group. This indicated that $N$. cyriacigeorgica seriously damage the cell membranes of bMECs with the passage of time.

\section{DNA Ladder Assessment}

DNA fragment is shown in Figure 2. There was no appearance of DNA ladder band in the bMECs of control group, 1, 3, and 6 $\mathrm{h}$ groups and also in $N$. cyriacigeorgica control group. But in the infected groups at 12 and $18 \mathrm{~h}$, distinct typical DNA ladder bands were observed. These results indicated that $N$. cyriacigeorgica could induce apoptosis/necrosis in bMECs and the apoptotic DNA fragment was observed after $12 \mathrm{~h}$ post-infection.

\section{Apoptosis/Necrosis Analysis}

Annexin V/PI double staining was used to analyze the early apoptotic cells and late apoptotic/necrotic cells. Figure 3 depicted limited apoptosis/necrosis at 1 and $3 \mathrm{~h}$ post-infection. The early apoptosis rate was increased significantly $(p<0.01)$ from $6 \mathrm{~h}$ post-infection compared with control group. There was a slight increase of apoptosis at $6 \mathrm{~h}$ post-infection; then the apoptotic/necrotic changes increased dramatically $(p<$ 0.01 ) at 12 and $18 \mathrm{~h}$ post-infection in comparison with the

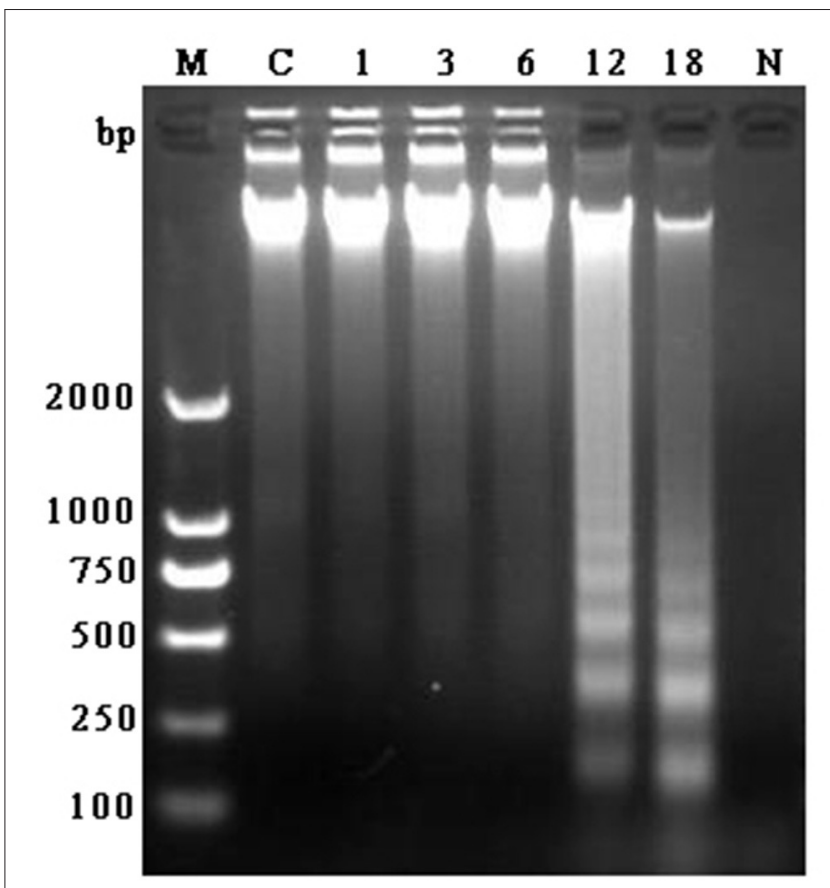

FIGURE 2 | Agarose gel of electrophoresis of DNA fragment obtained from bMECs at $1,3,6,12$, and $18 \mathrm{~h}$ post-infection, control group and N. cyriacigeorgica. M, Marker; C, Control group; 1-18, Cells infected with N. cyriacigeorgica for $1,3,6,12$, and $18 \mathrm{~h} ; \mathrm{N}, \mathrm{N}$. cyriacigeorgica.

control group. Furthermore, both at $12 \mathrm{~h}$ and $18 \mathrm{~h}$, the late apoptosis/necrosis rate was much higher $(p<0.01)$ than early apoptosis rate. Additionally, the total death rate at $18 \mathrm{~h}(52.26 \%)$ was significantly higher $(p<0.01)$ than that at $12 \mathrm{~h}(46.99 \%)$. These data suggested that $N$. cyriacigeorgica could cause both apoptosis and necrosis, which was seriously intensified in time dependent manner.

\section{Scanning Electron Microscopy (SEM)}

To further confirm the adhesion, invasion, LDH release and cell death, SEM was used to test the interaction of bMECs infected with $N$. cyriacigeorgica and the cell damages. There were no morphological changes in control group (Figure 4A). At $6 \mathrm{~h}$ post-infection, morphological changes were observed as mild disruption of the some bMECs and short Nocardia filaments adhered on the surface of cells (Figures 4B,C). At 12 and $18 \mathrm{~h}$ post-infection, bMECs were obvious shrinkage, cytomorphosis, desquamation, and cell membrane breakage, with spherical protrusion appearance on some cell surface, abundant growing mycelium covering the cells and filaments penetrating into cell membrane both from the extracellular and intracellular (Figures 4D-I). Particularly, at 6,12 , or $18 \mathrm{~h}$, SEM results demonstrated that microvilli on the cell surface were totally wrapped by Nocardia filaments (Figures $4 \mathbf{E}, \mathbf{H}, \mathbf{I}$ ). Thus, these changes to the cellular morphology suggested that the penetration and viability of $N$. cyriacigeorgica may be responsible for aforesaid cell damages. 


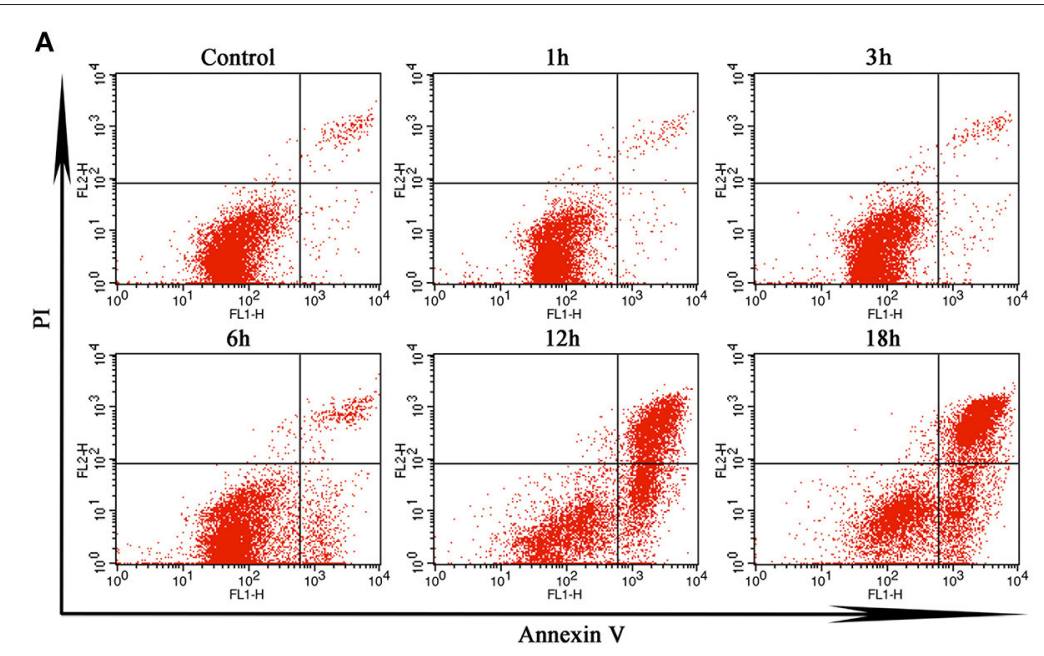

B

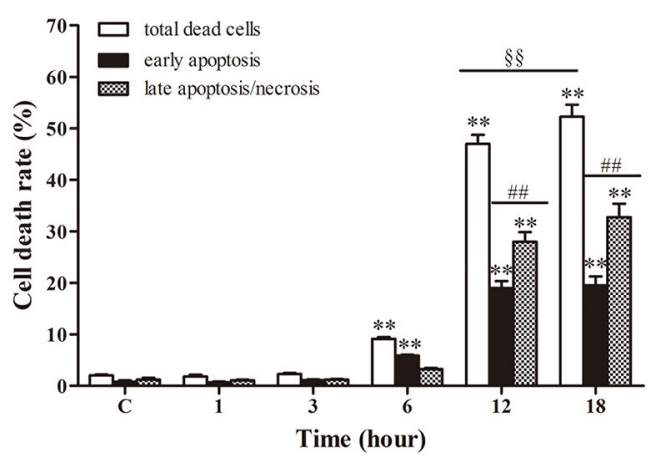

FIGURE 3 | Apoptosis and necrosis of bMECs analyzed by flow cytometry with annexin V/propidium iodide (PI) double staining. (A) Two dimensional scatter plots of FITC Annexin V vs. PI through flow cytometry. Cells stained negative for FITC Annexin V and PI in the lower left quadrant shows alive cells. Cells stained positive for FITC Annexin V and negative for PI in the lower right quadrant are representing early apoptosis. Cells stained positive for both FITC Annexin $V$ and $\mathrm{PI}$ in the upper right quadrant are the late apoptotic/necrotic cells. (B) Percentage of early apoptotic cells and late apoptotic/necrotic cells. Data were presented as Mean $\pm S D$ of three independent experiments. ${ }^{\star \star} P<0.01$ as compared with the control group. $\# \# P<0.01$ as compared between the rate of early and late apoptosis/necrosis at the same time point. ${ }^{\S \S P}<0.01$ indicates the significant differences in total cells death rate between 12 and $18 \mathrm{~h}$.

\section{Transmission Electron Microscopy (TEM)}

TEM was used to check the internalization of nocardial cells and ultrastructural changes in bMECs with $N$. cyriacigeorgica infection. The ultrastructure changes of infected cells are elaborated in Figure 5, which included swollen endoplasmic reticulum, cristae degeneration and swelling of mitochondria and also expansion of perinuclear space at $6 \mathrm{~h}$ post-infection (Figures 5D-F); while at $12 \mathrm{~h}$ of post infection, vesicle formation on the cell surface, rupturing of cell membrane, and nuclear membrane, chromatin clumping, fragmentation and margination of chromatin were noted (Figures 5G-I). Finally, serious disruption of cells, loss of organelles, and intramitochondrial dense granules accumulation were observed, at $18 \mathrm{~h}$ post-infection (Figures 5J-L). Furthermore, Nocardial cells were found both in cytoplasm and nucleus. These observations showed a process of progressive cell necrosis induced by clinical N. cyriacigeorgica infection.

\section{Mitochondrial Transmembrane Potential $(\Delta \Psi \mathrm{m})$ Assay}

Following a relatively stable state of $\Delta \Psi \mathrm{m}$ in the early stage $(1-6 \mathrm{~h})$ of nocardial infection, there was a remarkable decrease $(p<0.01)$ of $\Delta \Psi \mathrm{m}$ in the late stage of infection viz. 12-18 $\mathrm{h}$ in comparison with the control group (as shown in Figure 6).

\section{Western Blot Analysis}

The western blotting results of cytochrome c, caspase- 9 and caspase-3 are depicted in Figure 7. A gradual increase in mitochondrial cytochrome $\mathrm{c}$ release was observed after $1 \mathrm{~h}$ postinfection $(p<0.05)$, with significantly higher caspase- 9 activation $(p<0.01)$ from $1 \mathrm{~h}$ and markedly enhanced caspase- $3(p<0.05)$ activation from $3 \mathrm{~h}$ of infection as compared to the control group.

\section{Apoptosis Analysis in Parallel with the Growth of Intracellular N. cyriacigeorgica}

The growth of intracellular Nocardia showed that the apoptosis rate was increased significantly $(p<0.01)$ from $12 \mathrm{~h}$ compared with control group (Figures 8A,B). At 12 and $18 \mathrm{~h}$, most of the dead cells were at the early apoptotic stage $(p<0.01)$. In addition, the total death rate of bMECs at $18 \mathrm{~h}(19.70 \%)$ was significantly higher $(p<0.01)$ than at $12 \mathrm{~h}(15.80 \%)$. Strikingly, Gram staining showed that the Nocardia were short rod-shaped with no considerable growth during 1-6 h; nevertheless, they germinated into unique long mycelial form at 12 and $18 \mathrm{~h}$, leading to pathomorphological changes of infected cells (Figure 8C). Bacterial counting presented an interesting results that there were no significant difference of the number of total Nocardia at different incubation time compared with control group. Similar results for the enumeration of intracellular Nocardia were also found within $12 \mathrm{~h}$. This was in accordance with the apoptosis analysis, which presented that the apoptosis significantly increased at 12 and 18 $h$. The intracellular bacteria significantly decreased $(p<0.01)$ at $18 \mathrm{~h}$ compared with control group (Figure 8D). The unchanging number of Nocardia and the results of Gram staining revealed that both intracellular and extracellular $N$. cyriacigeorgica grew from small rods to mycelia rather than to reproduce during 18 $\mathrm{h}$ incubation (Figures 8C,D). During the robust growth phase of Nocardia at $12-18 \mathrm{~h}$, cell apoptosis was aggravated remarkably (Figures 8A-C).

\section{DISCUSSION}

Bacterial adhesion and invasion played important roles in establishing infection. The quantitative analysis of adhesion and invasion of $N$. cyriacigeorgica and visualized results of 

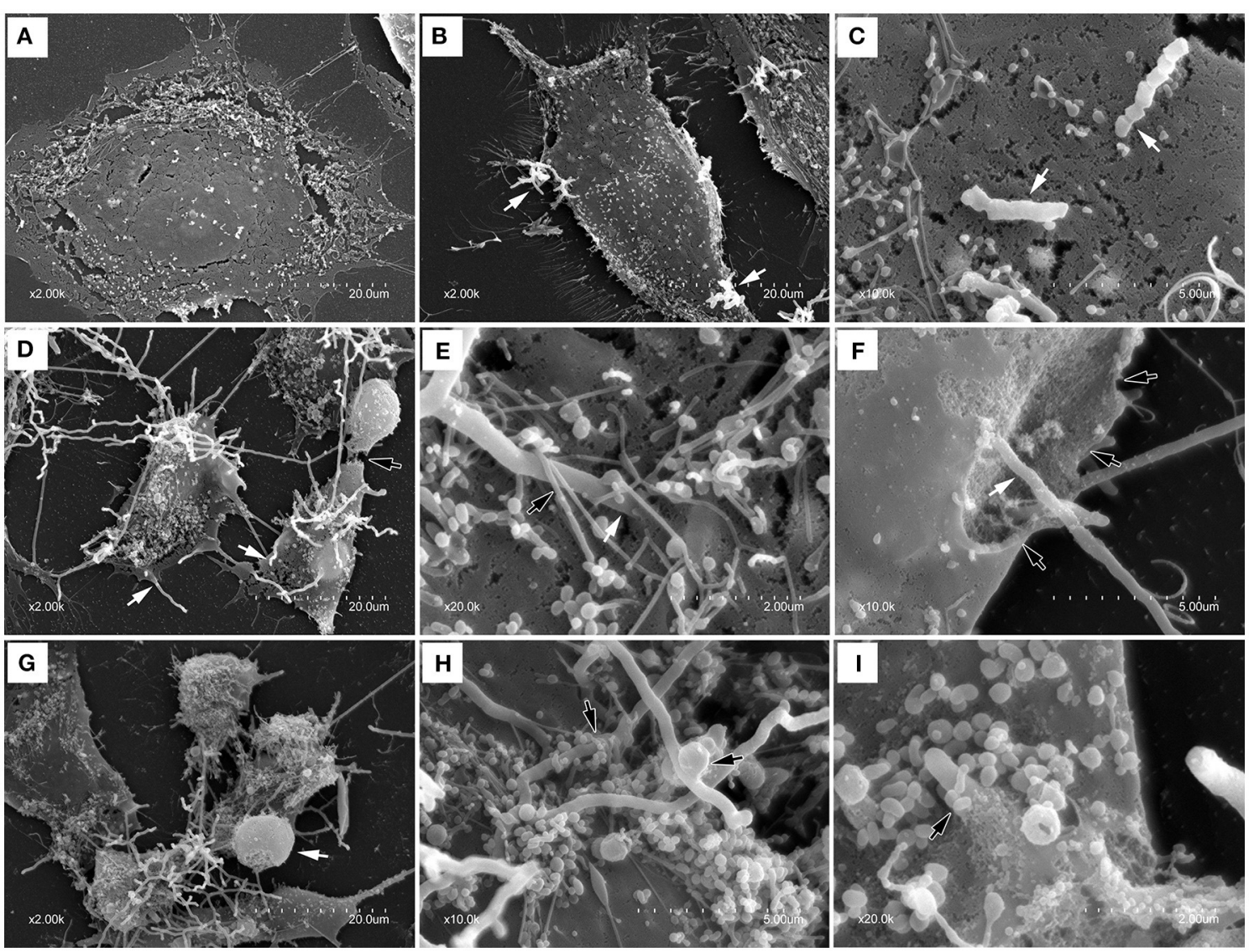

FIGURE 4 | Scanning electron photomicrographs showing interaction of bMECs infected with $\mathbf{N}$. cyriacigeorgica. (A) demonstrates the normal cell without N. cyriacigeorgica infection that adherent to coverslip. (B) The cell with folding edge and several N. cyriacigeorgica filaments (white arrows) adhered on the cell surface at 6 h. (C) Apical attachment of N. cyriacigeorgica to cell surface at 6 h. (D) Atrophic and fragmented cells (black arrow) following long N. cyriacigeorgica filaments throughout cells (white arrows) at $12 \mathrm{~h}$. (E) The white arrow showing $N$. cyriacigeorgica filament penetrating into the cell membrane and the black arrow presenting microvilli trapping N. cyriacigeorgica filament at $12 \mathrm{~h}$. (F) A gap (black arrows) on the cell membrane with $\mathrm{N}$. cyriacigeorgica filaments inside it (white arrows) at $12 \mathrm{~h}$.

(G) Shrinking cells coated with numerous N. cyriacigeorgica filaments. A nucleus-like spherical protrusion observed on the cell surface (white arrow) at $18 \mathrm{~h}$. (H)

Microvilli wrapped N. cyriacigeorgica filaments at $18 \mathrm{~h}$. (I) A tip of intracellular N. cyriacigeorgica filament penetrated through the cell membrane at $18 \mathrm{~h}$.

SEM and TEM showed that $N$. cyriacigeorgica possess the adhesion and penetration abilities. Significantly, we observed that $N$. cyriacigeorgica could promptly adhere to and penetrated into the bMECs within $10 \mathrm{~min}$. These results were in accordance with a previous study which reported $68 \%$ adherence rate and $70.8 \%$ penetration rate of $N$. asteroides GUH-2 (N. cyriacigeorgica GUH-2) to endothelial cells in brain within 15-25 min exposure period (Beaman and Ogata, 1993). The findings of this study and some previous studies suggested that Nocardia has the capability of adhesion, invasion and viability within various host cells both in vitro and in vivo (Beaman and Ogata, 1993; Beaman and Beaman, 1994, 1998).

In the log-phase $N$. cyriacigeorgica depicted strong penetrative and adhesion ability than the stationary-phase and only live log-phase organisms can penetrate into cells (Beaman and Beaman, 1998). Nocardia can adhere to cells through surface adhesion molecules, live, and heat-killed Nocardia both can bind to the cell surface. Most of studies demonstrated that a filamentous tip associated $43-\mathrm{kDa}$ protein of $N$. asteroides
GUH-2 played a dominant role in attachment and invasion to pulmonary epithelial cells and HeLa cells (Beaman and Beaman, 1998). The antiserum against the $43-\mathrm{kDa}$ antigen inhibited apical adhesion and penetration to pulmonary epithelial cells, and prevented spread to the brain. Through gene sequence analysis of $N$. cyriacigeorgica, a series of putative mammalian cell entry proteins (mce) of $N$. cyriacigeorgica (Vera-Cabrera et al., 2013; Zoropogui et al., 2013) were found and these proteins were essential for pathogens to attach, enter and survive in the host cells (Zhang and Xie, 2011). Additionally, adhesion of Nocardia was associated with the cell surface structures, such as microvilli. Cell surface provides a direct connection with the bacteria. As evident from the SEM results, this presented that the microvilli of bMECs can capture Nocardia. This phenomenon was also observed previously on other cells (Beaman and Beaman, 1994, 1998).

After exposure to bMECs, $N$. cyriacigeorgica infection led to perforation in cell membranes, release of LDH, fragmentation of 

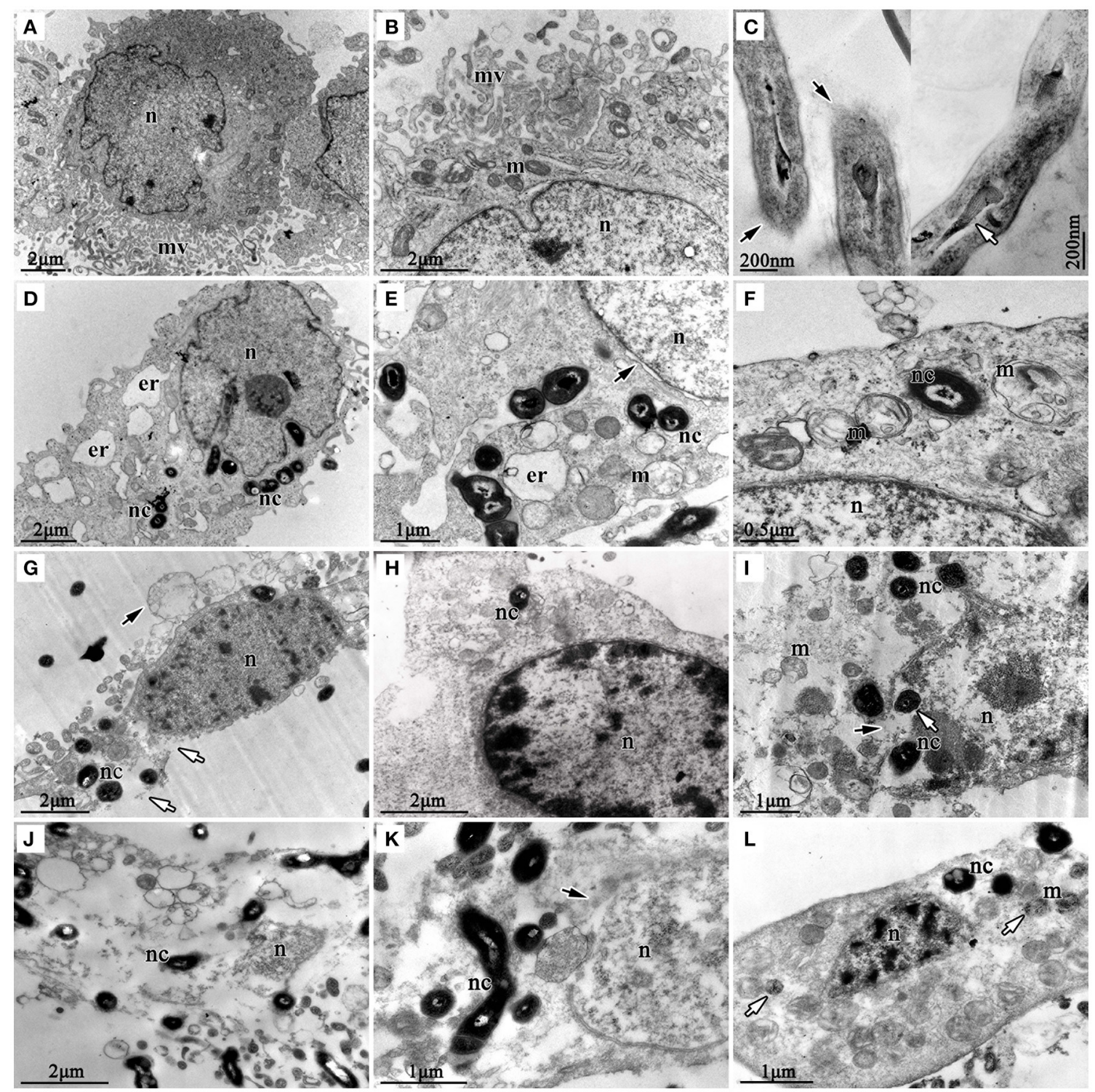

FIGURE 5 | Transmission electron photomicrographs showing ultrastructural pathological changes in bMECs co-cultured with $N$. cyriacigeorgica. (A,B) are the non-infected cells that show rich microvilli on cell surface and abundant mitochondria in cytoplasm, non-infected cells. (C) is the longitudinal sections of N. cyriacigeorgica incubated in DMEM/F12 with 4\% FBS which depict the tips of log-phase N. cyriacigeorgica presenting hazy cell wall (black arrows) compared with that in the trunk. The white arrow is showing tubular-like nucleus of $N$. cyriacigeorgica. (D) Nocardial cells in cytoplasm and swollen endoplasmic reticulum at 6 h. (E) Flocculent densities in swollen and round mitochondria, expansion of perinuclear space (black arrow) at $6 \mathrm{~h}$. (F) Mitochondria with electron density decreasing and crista degeneration at $6 \mathrm{~h}$. (G) Vesicles on the cell surface (black arrow), chromatin condensation and fragmentation, cell membrane breakage (white arrows) at $12 \mathrm{~h}$. (H) Chromatin condensation and accumulation at $12 \mathrm{~h}$. (I) Mitochondria disruption, nuclear membrane rupture (black arrow); nocardial cells in cell nucleus (white arrow) at $12 \mathrm{~h}$. (J) Cell disruption with loss of organelles at $18 \mathrm{~h}$. (K) The nuclear membrane ruptures and disruption (black arrow) at $18 \mathrm{~h}$. (L) Mitochondrial pyknosis and intramitochondrial dense granules accumulation, chromatin condensation and fragmentation, loss of microvilli (white arrow) at $18 \mathrm{~h}$. $\mathrm{nc}-\mathrm{N}$. cyriacigeorgica, $n$-nucleus, $m$-mitochondrion, $m v$-microvillus, er-endoplasmic reticulum.

nuclear membrane, chromatin condensation and mitochondrial degeneration, which can caused untimely collapse of the entire cell. Previous studies suggested that the pathogenicity of Nocardia is dependent on the virulence factors and toxins. The putative virulence factors of $N$. cyriacigeorgica included catalase, superoxide dismutase, hemolysin, invasion, protease, mammalian cell proteins (mec), mycolic acids, nitrate reductase, and PE/PPE/PGRS family proteins through gene analysis (Vera-Cabrera et al., 2013; Zoropogui et al., 2013), among most of them had been proved. Catalase and superoxide dismutase of $N$. cyriacigeorgica probably acted important roles in defense against deleterious superoxide and reactive oxygen species (ROS) during intracellular killing by phagocytes (Wu et al., 2006). The presence of nitrate reductase for 

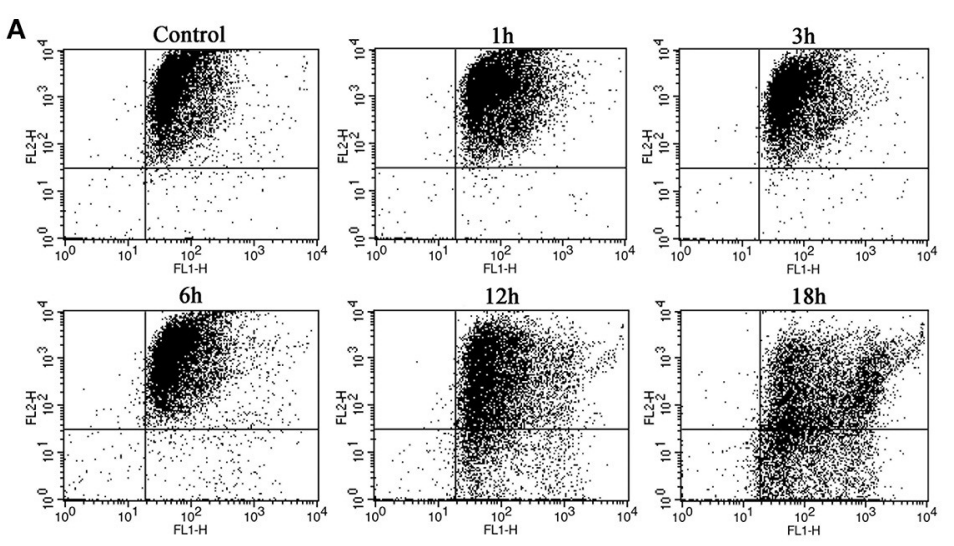

B

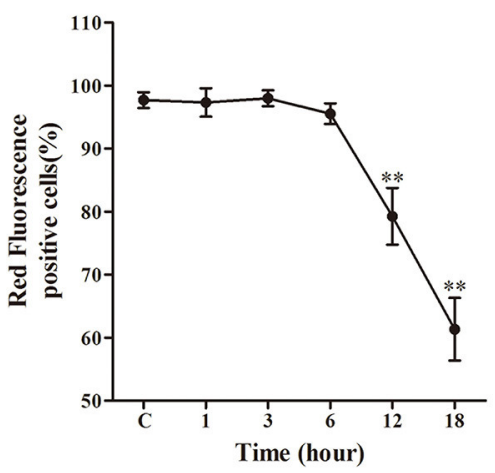

FIGURE 6 | Mitochondrial transmembrane potential $(\Delta \Psi \mathbf{m})$ assay of bMECs co-cultured with $\boldsymbol{N}$. cyriacigeorgica. (A) $\Delta \Psi \mathrm{m}$ determined using JC-1 via flow cytometry. Red fluorescence positive cells in the upper right quadrant and green fluorescence positive cells in the lower right quadrant. (B) The percentage of red fluorescence positive cells. Results were presented as Mean $\pm S D$ of three independent experiments. ${ }^{* *} P<0.01$ as compared to the control group.

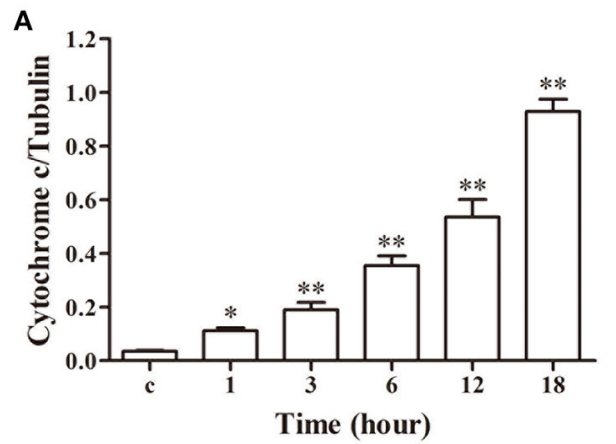

C

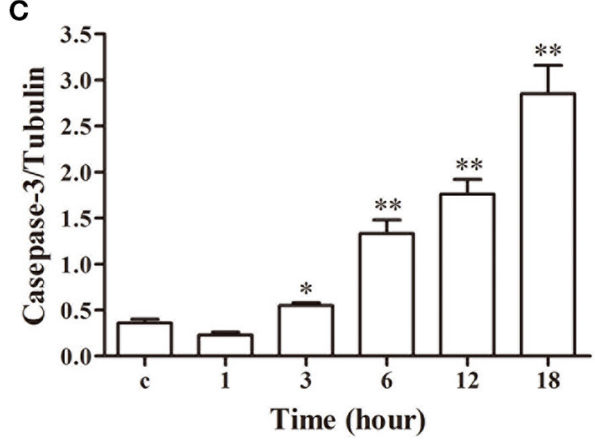

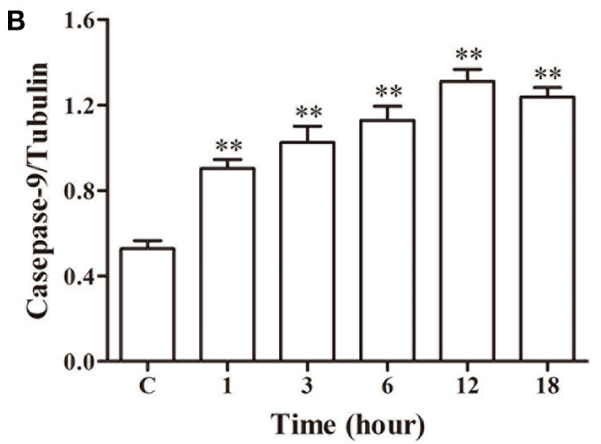

D

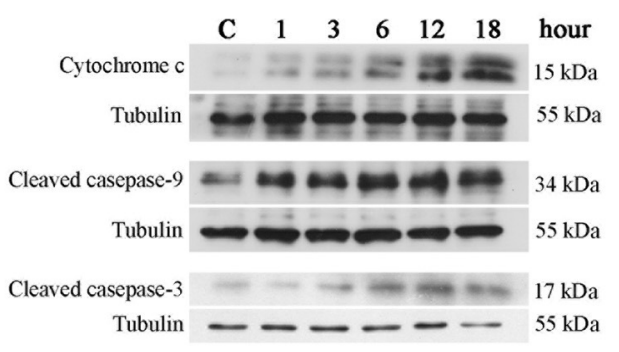

FIGURE 7 | Protein expression assay of bMECs incubated with $\mathbf{N}$. cyriacigeorgica by western blot analysis. (A) The release of mitochondrial cytochrome C. (B) The expression of cleaved caspase-9. (C) The expression of cleaved caspase-3. (D) The western blot assays of cytochrome c, cleaved caspase-9 and cleaved caspase-3 expression at 1, 3, 6, 12, and $18 \mathrm{~h}$ after $N$. cyriacigeorgica infection in bMECs. Results were presented as Mean $\pm S D$ of three independent experiments. ${ }^{\star} P<0.05,{ }^{* *} P<0.01$ as compared with the control group.

N. cyriacigeorgica suggested an ability to grow under lowoxygen conditions in stimulated macrophages (Zoropogui et al., 2013). Significantly, mycolic acids, the major and specific lipid components of cell envelope, have important implications in the pathogenesis of Mycobacterium, Nocardia and Rhodococcus, and Corynebacterium (Elamin et al., 2012; Verschoor et al., 2012). The cell wall-associated lipids of Nocardia induced the production of the proinflammatory cytokines and inhibited important macrophage microbicidal effects (Trevino-Villarreal et al., 2012).

Bacteria often elicited cell apoptosis as a survival strategy. Pathogens have evolved a series of toxins and virulence factors to modulate host cell death (Lamkanfi and Dixit, 2010). During the first $6 \mathrm{~h}$ of Nocardia infection, there were only several 

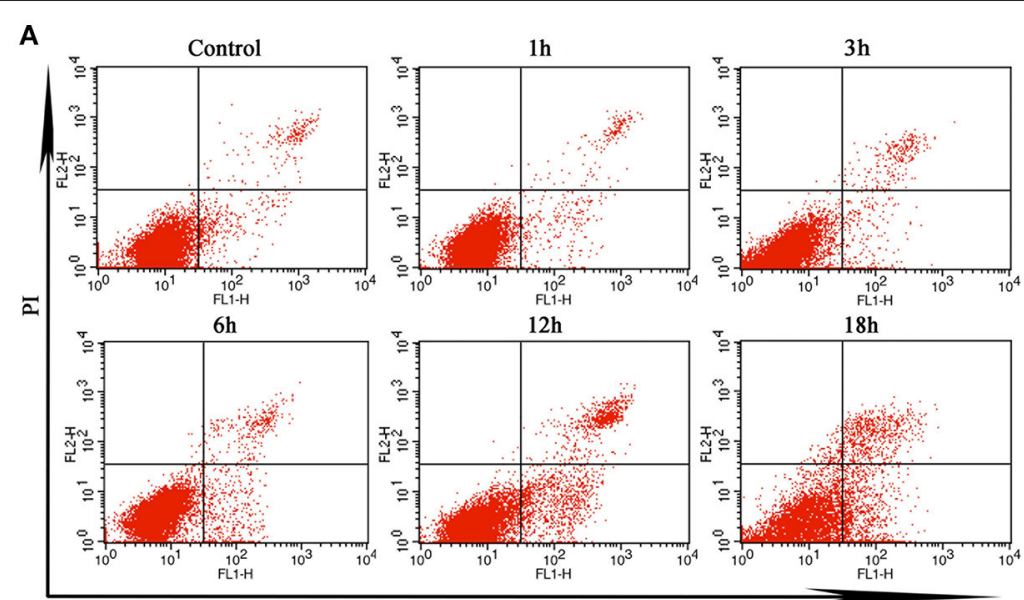

B
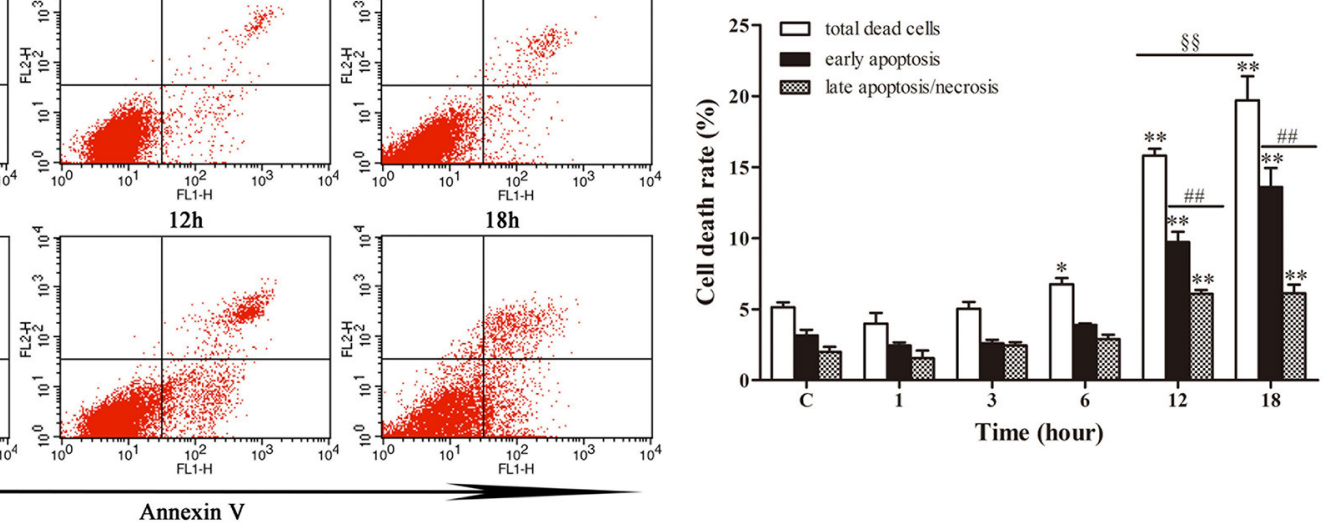

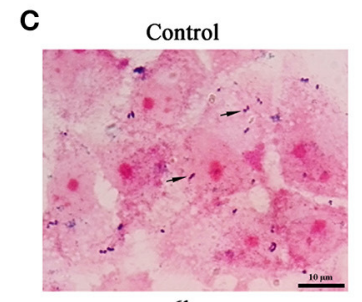

$6 \mathrm{~h}$

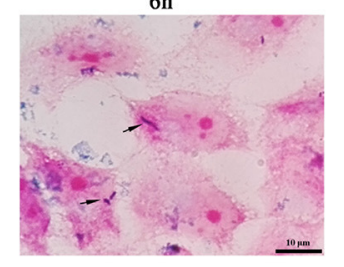

$1 \mathrm{~h}$

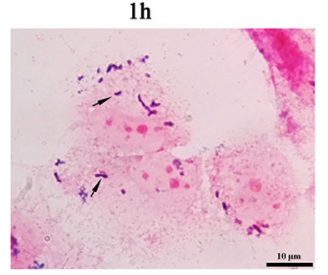

$12 \mathrm{~h}$

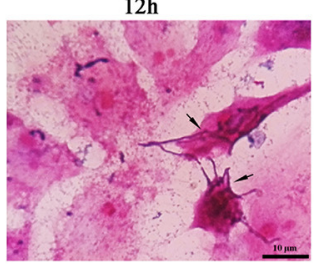

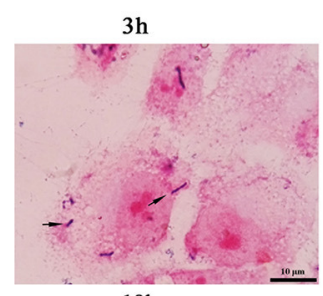

$18 \mathrm{~h}$

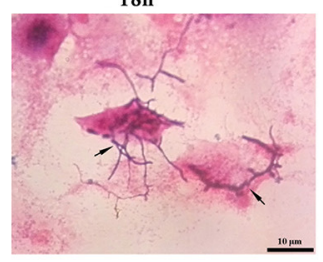

D

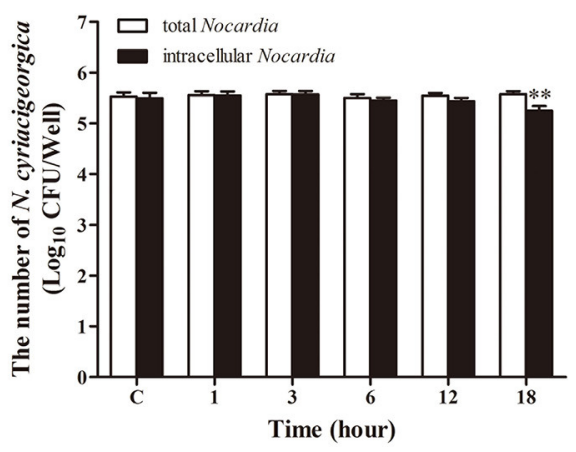

FIGURE 8 | Apoptosis analysis in parallel with the growth of intracellular $\boldsymbol{N}$. cyriacigeorgica. (A) Two dimensional Scatter plots of FITC Annexin $V$ vs. PI through flow cytometry. (B) Percentage of early apoptotic cells and late apoptotic/necrotic cells. (C) Gram staining of bMECs and Nocardia under light microscope. From 1-6 h, only few short rods of Nocardia can be observed (black arrows); while from 12 to 18 h, short rods grew into long mycelia (black arrows). (D) The number of total Nocardia and intracellular Nocardia. Data were presented as Mean $\pm S D$ of at least three independent experiments. ${ }^{\star} P<0.05$, ${ }^{\star \star} P<0.01$ as compared with the control group. $\# \# P<0.01$ as compared between the rate of early and late apoptosis/necrosis at the same time point. ${ }^{\S \S} P<0.01$ represents the significant differences in total cells death rate between 12 and $18 \mathrm{~h}$.

short nocardial filaments on the cell surface imparting mild morphological changes in bMECs, and there were also no obvious cytotoxic effects and $\Delta \Psi \mathrm{m}$, following no or low number of dead cells. Nevertheless, during the late stage of infection, short nocardial mycelia grew into long and strong mycelia, which can invade and penetrate into the bMECs, and even grew within cells; simultaneously, $N$. cyriacigeorgica was found to significantly elicit cell apoptosis, and exacerbated changes in cell morphology and ultrastructure, with a typical fragmentation of DNA and a collapse of $\Delta \Psi \mathrm{m}$ from $12 \mathrm{~h}$. Besides, there was robust release of LDH from $12 \mathrm{~h}$, which was associated with the serious cell membrane breakage and the large number of late apoptotic/necrotic cell in this period. A previous study demonstrated that live Nocardia can invade into cells and significantly increase in apoptosis rate in infected cells compared to heat-killed Nocardia (Barry and Beaman, 2007). Considering these above results, we can assume that the penetration and aggressive growth of $N$. cyriacigeorgica mycelia might be one of the factors to induce death of bMECs. Additionally, on PC12 cells, Nocardia culture filtrate was found to induce apoptotic morphology after $24 \mathrm{~h}$-treatment and increased release of LDH after $48 \mathrm{~h}$ (Loeffler et al., 2004), indicated that the metabolites of Nocardia are toxic to cells.

An extra experiment was performed to know the cytopathic and apoptotic effects of only intracellular Nocardia, which was coupled with study regarding the growth of intracellular bacteria. For this purpose the extracellular bacteria were killed with amikacin and apopotosis and growth of the intracellular bacteria was evaluated. Interesting, the results showed that apoptosis and bacterial growth have a parallel relationship. These effects were significantly exhibited during 12 and $18 \mathrm{~h}$. Importantly, there was no significant changes in the total number of Nocardia but the bacteria grew into mycelial form, imparting cell damage and apoptosis. At 12 and $18 \mathrm{~h}$ of infection, a rapid 


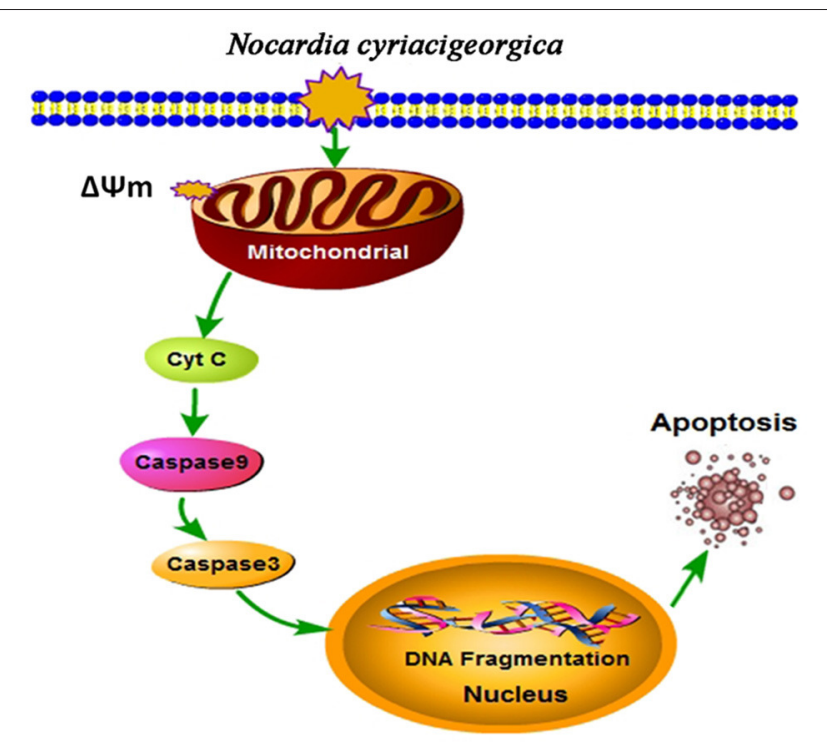

FIGURE 9 | Schematic illustration of mitochondrial-caspase induced apoptosis. Depolarization of mitochondrial transmembrane $(\Delta \Psi \mathrm{m})$ causes release of cytochrome $\mathrm{c}$ (Cyt $\mathrm{C}$ ), which may initiate caspase cascade. Cyt $\mathrm{C}$ bonds with apoptotic protease-activating factor 1 (Apaf-1) (not shown in the Figure) and activates caspase-9, this cleaves and activates caspase-3, which triggers the apoptosis. Translocation of endonuclease $\mathrm{G}$ (Endo $\mathrm{G}$ ) from the mitochondria to the nucleus and nuclear activation of DNA fragmentation factor (DFF) (not shown in the Figure) caused by caspase activation induced nucleosomal DNA fragmentation during apoptosis (Kitazumi and Tsukahara, 2011).

growth of Nocardia was noted without reproduction, which indicated that the aggressive growth of intracellular Nocardia may act as an important role in the cell injury leading to cell death.

These data suggested that $N$. cyriacigeorgica infection and invasion can induce both apoptotic and necrotic changes in bMECs after $6 \mathrm{~h}$, corroborating with the previous findings in which Nocardia induced apoptosis in PC12 cells and HeLa cells (Tam et al., 2002; Loeffler et al., 2004; Barry and Beaman, 2007). In Hela and PC12 cells, live Nocardia promoted a significant DNA fragmentation during 6 h-exposure period (Tam et al., 2002; Barry and Beaman, 2007). Previous studies also showed that Nocardia localized in substantia nigra and then underwent a rapid growth, inducing apoptosis of dopaminergic cells and failure of inflammatory response in $24 \mathrm{~h}$ (Kohbata and Beaman, 1991; Tam et al., 2002). Cell apoptosis is a double-edged sword both for host and bacteria during infection. For the host, cell apoptosis is a defense mechanism against pathogenic bacteria to prevent the release of intracellular bacteria and the spread of bacteria. Whereas, for bacteria, they induce cell apoptosis to block the spilling of cellular contents, to suppress the motivation of inflammatory reaction and then to evade host defenses. Several bacterial pathogens can cause cell apoptosis; whereas, many intracellular pathogens, such as Mycobacterium tuberculosis, can protect infected cells from apoptosis for its survival (Faherty and Maurelli, 2008; Butler et al., 2012). However, in the process of infection, N. cyriacigeorgica, being an intracellular pathogen, caused apoptosis and necrosis in bMECs.

The ultrastructural pathology of TEM showed the mitochondrial damage. To further validate our results, the collapse of $\Delta \Psi \mathrm{m}$ and release of mitochondrial cytochrome $\mathrm{c}$ were determined, presenting a decrease of $\Delta \Psi \mathrm{m}$ and an increase of cytochrome c release. On the other hand, western blot analysis suggested the promotion of casepase- 9 and casepase- 3 activation. Likewise, similar effects on mitochondria and caspase- 3 activity have been proved in the Nocardia-induced Hela apoptosis at a MOI of 5:1co-cultured for $5 \mathrm{~h}$ (Barry and Beaman, 2007). Altogether, from these findings we can draw the conclusion that $N$. cyriacigeorgica can induce apoptosis of bMECs mediated by a mitochondria-caspase dependent pathway. Mitochondrial dysfunction to release proteins from the intermembrane space into the cytosol is the pivotal focus in the process of apoptosis (Wang and Youle, 2009). As for apoptotic signaling, cytochrome $\mathrm{c}$ was a critical apoptogenic factor and was capable of initiating the caspase cascade (Kagan et al., 2009). Normally, cytochrome $\mathrm{c}$ is localized in the mitochondrial intermembrane space. During the infection of $N$. cyriacigeorgica, the opening of the mitochondrial permeability transition pore induced depolarization of mitochondrial transmembrane $\Delta \Psi \mathrm{m}$, release of apoptogenic factors and loss of oxidative phosphorylation (Tait and Green, 2010). Cytochrome c transposed from the mitochondrial membrane space to the cytosol; then bond to apoptotic protease-activating factor 1 (Apaf-1), triggered the formation of the apoptosome, inducing recruitment and activation of caspase-9. Caspase-9 cleaves and activates executioner caspase-3, which triggers the apoptosis ( $\mathrm{Ow}$ et al., 2008; Tait and Green, 2010). Simultaneously, translocation of endonuclease $G$ (Endo $G$ ) from the mitochondria to the nucleus and nuclear activation of DNA fragmentation factor (DFF) caused by caspase activation induced nucleosomal DNA fragmentation during apoptosis (Kitazumi and Tsukahara, 2011). DNA fragmentation is a hallmark of apoptosis and is one of the last consequences of apoptosis (Kitazumi and Tsukahara, 2011). The major schematic representation of mitochondrial-caspase induced apoptotic pathway studied in this work is elucidated in Figure 9.

In summary, these results of the present study demonstrated that clinical $N$. cyriacigeorgica was able to adhere and invade the bMECs, causing disruption of cell membrane and mitochondrial degeneration. Our data supports the hypothesis that $N$. cyriacigeorgica induced host cell death via an apoptotic mechanism and the later stage of $N$. cyriacigeorgica infection followed mitochondrial-dependent apoptotic pathway in bMECs. These findings provide that the apoptosis of bMECs was induced via triggering the caspase cascade and might present important insights into the mechanisms of $N$. cyriacigeorgica infections in bovine mammary tissues.

\section{ETHICS STATEMENT}

The present study was conducted in accordance with the ethical guide lines of China Agricultural University (CAU), Beijing. 
Furthermore, prior to the initiation of this work, proper approval was granted by the departmental committee of College of Veterinary Medicine, CAU.

\section{AUTHOR CONTRIBUTIONS}

WC planned, performed the experiments, and then wrote manuscript. XG and YL performed the experiments, LZ and TA helped in analysis of flow cytometry experiments, GL collaborated in writing manuscript,

\section{REFERENCES}

Al Akhrass, F., Hachem, R., Mohamed, J. A., Tarrand, J., Kontoyiannis,D. P., Jyotsna, C., et al. (2011). Central venous catheter-associated Nocardia bacteremia in cancer patients. Emerg. Infect. Dis. 17, 1651-1658. doi: $10.3201 /$ eid1709.101810

Ambrosioni, J., Lew, D., and Garbino, J. (2010). Nocardiosis: updated clinical review and experience at a tertiary center. Infection 38, 89-97. doi: 10.1007/s15010-009-9193-9

Ashida, H., Mimuro, H., Ogawa, M., Kobayashi, T., Sanada, T., Kim, M., et al. (2011). Cell death and infection: a double-edged sword for host and pathogen survival. J. Cell Biol. 195, 931-942. doi: 10.1083/jcb.201108081

Barry, D. P., and Beaman, B. L. (2007). Nocardia asteroides strain GUH-2 induces proteasome inhibition and apoptotic death of cultured cells. Res. Microbiol. 158, 86-96. doi: 10.1016/j.resmic.2006.11.001

Bättig, U., Wegmann, P., Meyer, B., and Penseyres, J. (1989). Nocardia mastitis in cattle. 1. Clinical observations and diagnosis in 7 particular cases. Schweizer Archiv. Tierheilkunde 132, 315-322.

Bawa, B., Bai, J., Whitehair, M., Purvis, T., and DeBey, B. M. (2010). Bovine abortion associated with Nocardia farcinica. J. Vet. Diagn. Invest. 22, 108-111. doi: $10.1177 / 104063871002200122$

Bayles, K. W., Wesson, C. A., Liou, L. E., Fox, L. K., Bohach, G. A., and Trumble, W. R. (1998). Intracellular staphylococcus aureus escapes the endosome and induces apoptosis in epithelial cells. Infect. Immun. 66, 336-342.

Beaman, B. L., and Beaman, L. (1994). Nocardia species: host-parasite relationships. Clin. Microbiol. Rev. 7, 213-264. doi: 10.1128/CMR.7. 2.213

Beaman, B. L., and Beaman, L. (1998). Filament tip-associated antigens involved in adherence to and invasion of murine pulmonary epithelial cells in vivo and HeLa cells in vitro by Nocardia asteroides. Infect. Immun. 66, 4676-4689.

Beaman, B. L., and Ogata, S. A. (1993). Ultrastructural analysis of attachment to and penetration of capillaries in the murine pons, midbrain, thalamus, and hypothalamus by Nocardia asteroides. Infect. Immun. 61, 955-965.

Beaman, B. L., and Sugar, A. M. (1983). Nocardia in naturally acquired and experimental infections in animals. J. Hyg. 91, 393-419. doi: 10.1017/S002217 2400060447

Beaman, B. L., and Tam, S. (2008). An unusual murine behavior following infection with log-phase Nocardia asteroides type 6 strain GUH-2 (Nocardia cyriacigeorgica GUH-2). Microbes Infect. 10, 840-843. doi: 10.1016/j.micinf. 2008.04.007

Brown, J. M., Cowley, K. D., Manninen, K. I., and McNeil, M. M. (2007). Phenotypic and molecular epidemiologic evaluation of a Nocardia farcinica mastitis epizootic. Vet. Microbiol. 125, 66-72. doi: 10.1016/j.vetmic.2007.04.044

Brown-Elliott, B. A., Conville, P., and Wallace, R. J. (2015). Current status of Nocardia taxonomy and recommended identification methods. Clin. Microbiol. Newslett. 37, 25-32. doi: 10.1016/j.clinmicnews.2015.01.007

Butler, R. E., Brodin, P., Jang, J., Jang, M. S., Robertson, B. D., Gicquel, B., et al. (2012). The balance of apoptotic and necrotic cell death in Mycobacterium tuberculosis infected macrophages is not dependent on bacterial virulence. PLoS ONE 7:e47573. doi: 10.1371/journal.pone.0047573

Chapman, G., Beaman, B. L., Loeffler, D. A., Camp, D. M., Domino, E. F., Dickson, D. W., et al. (2003). In situ hybridization for detection of nocardial 16S rRNA: reactivity within intracellular inclusions in experimentally infected cynomolgus
MS and TA revised and corrected the manuscript, JG analyzed the data and $\mathrm{BH}$ designed and evaluated the research. All authors have read and approved the final manuscript.

\section{FUNDING}

This research was supported by Ministry of Education in China major project (No. 313054) and the National Natural Science Foundation of China (No. 3151101034 and NO. 31572587). monkeys-and in Lewy body-containing human brain specimens. Exp. Neurol. 184, 715-725. doi: 10.1016/s0014-4886(03)00337-6

Condas, L. A., Ribeiro, M. G., Yazawa, K., de Vargas, A. P. C., Salerno, T., Giuffrida, R., et al. (2013). Molecular identification and antimicrobial susceptibility of Nocardia spp. isolated from bovine mastitis in Brazil. Vet. Microbiol. 167, 708-712. doi: 10.1016/j.vetmic.2013.08.019

Conville, P. S., and Witebsky, F. G. (2011). "Nocardia, Rhodococcus, Gordonia, Actinomadura, Streptomyces, and other aerobic actinomycetes," in Manual of Clinical Microbiology, 10th Ed (Washington, DC: ASM Press), 443-471.

Cook, J., and Holliman, A. (2004). Mastitis due to Nocardia asteroides in a UK dairy herd following restocking after FMD. Vet. Rec. 154, 267-268. doi: $10.1136 /$ vr.154.9.267

Dego, O. K., Van Dijk, J. E., and Nederbragt, H. (2002). Factors involved in the early pathogenesis of bovine Staphylococcus aureus mastitis with emphasis on bacterial adhesion and invasion. A review. Vet. Q. 24, 181-198. doi: 10.1080/01652176.2002.9695135

Dohoo, I. (1989). Nocardia spp. mastitis in Canada. Can. Vet. J. 30, 969.

Elamin, A. A., Stehr, M., and Singh, M. (2012). Lipid droplets and Mycobacterium leprae infection. J. Pathog. 2012:361374. doi: 10.1155/2012/361374

Elmore, S. (2007). Apoptosis: a review of programmed cell death. Toxicol. Pathol. 35, 495-516. doi: 10.1080/01926230701320337

Faherty, C. S., and Maurelli, A. T. (2008). Staying alive: bacterial inhibition of apoptosis during infection. Trends Microbiol. 16, 173-180. doi: 10.1016/j.tim.2008.02.001

Galluzzi, L., Vitale, I., Abrams, J. M., Alnemri, E. S., Baehrecke, E. H., Blagosklonny, M. V., et al. (2012). Molecular definitions of cell death subroutines: recommendations of the Nomenclature Committee on Cell Death 2012. Cell Death Differ. 19, 107-120. doi: 10.1038/cdd.2011.96

Hamid, M. E. (2012). Epidemiology, pathology, immunology and diagnosis of bovine farcy: a review. Prev. Vet. Med. 105, 1-9. doi: 10.1016/j.prevetmed.2012. 01.004

Hamid, M., El Sanousi, S., Minnikin, D., and Goodfellow, M. (1998). Isolation of Nocardia farcinica from zebu cattle suffering from mastitis in Sudan. Sudan J. Vet. Sci. Anim. Husb. 37, 66-71.

Hashemi-Shahraki, A., Heidarieh, P., Bostanabad, S. Z., Hashemzadeh, M., Feizabadi, M. M., Schraufnagel, D., et al. (2015). Genetic diversity and antimicrobial susceptibility of Nocardia species among patients with nocardiosis. Sci. Rep. 5:17862. doi: 10.1038/srep17862

Holland, S. M. (2010). Chronic granulomatous disease. Clin. Rev. Allergy Immunol. 38, 3-10. doi: 10.1007/s12016-009-8136-z

Kagan, V. E., Bayır, H. A., Belikova, N. A., Kapralov, O., Tyurina, Y. Y., Tyurin, V. A., et al. (2009). Cytochrome c/cardiolipin relations in mitochondria: a kiss of death. Free Radic. Biol. Med. 46, 1439-1453. doi: 10.1016/j.freeradbiomed.2009.03.004

Kitazumi, I., and Tsukahara, M. (2011). Regulation of DNA fragmentation: the role of caspases and phosphorylation. FEBS J. 278, 427-441. doi: 10.1111/j.1742-4658.2010.07975.x

Kohbata, S., and Beaman, B. L. (1991). L-dopa-responsive movement disorder caused by Nocardia asteroides localized in the brains of mice. Infect. Immun. $59,181-191$.

Kohbata, S., Emura, S., and Kadoya, C. (2009). Filterable forms of Nocardia: a preferential site of infection in the mouse brain. Microbes Infect. 11, 744-752. doi: 10.1016/j.micinf.2009.04.013 
Lamkanfi, M., and Dixit, V. M. (2010). Manipulation of host cell death pathways during microbial infections. Cell Host Microbe 8, 44-54. doi: 10.1016/j.chom.2010.06.007

Lira, R. M. M., Flores, A. Y. L., Carmona, M. C. S., and Stern, A. O. (2016). Experimental granulomatous pulmonary nocardiosis in BALB/C Mice. PLoS ONE 11:e0157475. doi: 10.1371/journal.pone.0157475

Liu, W. L., Lai, C. C., Ko, W. C., Chen, Y. H., Tang, H. J., Huang, Y. L., et al. (2011). Clinical and microbiological characteristics of infections caused by various Nocardia species in Taiwan: a multicenter study from 1998 to 2010. Eur. J. Clin. Microbiol. Infect. Dis. 30, 1341-1347. doi: 10.1007/s10096-011-1227-9

Loeffler, D. A., Camp, D. M., Qu, S., Beaman, B. L., and LeWitt, P. A. (2004). Characterization of dopamine-depleting activity of Nocardia asteroides strain GUH-2 culture filtrate on PC12 cells. Microb. Pathog. 37, 73-85. doi: 10.1016/j.micpath.2004.05.001

Meester, I., Rosas-Taraco, A. G., and Salinas-Carmona, M. C. (2014). Nocardia brasiliensis induces formation of foamy macrophages and dendritic cells in vitro and in vivo. PLoS ONE 9:e100064. doi: 10.1371/journal.pone.0100064

Ow, Y. P., Green, D. R., Hao, Z., and Mak, T. W. (2008). Cytochrome c: functions beyond respiration. Nat. Rev. Mol. Cell. Biol. 9, 532-542. doi: 10.1038/nrm2434

Pereyra, E. A., Picech, F., Renna, M. S., Baravalle, C., Andreotti, C. S., Russi, R., et al. (2016). Detection of Staphylococcus aureus adhesion and biofilm-producing genes and their expression during internalization in bovine mammary epithelial cells. Vet. Microbiol. 183, 69-77. doi: 10.1016/j.vetmic.2015.12.002

Pisoni, G., Locatelli, C., Alborali, L., Rosignoli, C., Allodi., S., Riccaboni, P., et al. (2008). Short communication: outbreak of Nocardia neocaledoniensis mastitis in an Italian dairy herd. J. Dairy Sci. 91, 136-139. doi: 10.3168/jds.2007-0477

Pöhlmann-Dietze, P., Ulrich, M., Kiser, K. B., Döring, G., Lee, J. C., Fournier, J. M., et al. (2000). Adherence of Staphylococcus aureus to endothelial cells: influence of capsular polysaccharide, global regulatoragr, and bacterial growth phase. Infect. Immun. 68, 4865-4871. doi: 10.1128/IAI.68.9.4865-4871.2000

Ribeiro, M. G., Salerno, T., Mattos-Guaraldi, A. L. D., Camello, T. C. F., Langoni, H., Siqueira, A. K., et al. (2008). Nocardiosis: an overview and additional report of 28 cases in cattle and dogs. Rev. Inst. Med. Trop. Sao Paulo 50, 177-185. doi: 10.1590/S0036-46652008005000004

Sullivan, D. C., and Chapman, S. W. (2010). Bacteria that masquerade as fungi: actinomycosis/nocardia. Proc. Am. Thorac. Soc. 7, 216-221. doi: $10.1513 /$ pats.200907-077AL

Tait, S. W., and Green, D. R. (2010). Mitochondria and cell death: outer membrane permeabilization and beyond. Nat. Rev. Mol. Cell Biol. 11, 621-632. doi: $10.1038 / \mathrm{nrm} 2952$

Tam, S., Barry, D. P., Beaman, L., and Beaman, B. L. (2002). Neuroinvasive Nocardia asteroides GUH-2 induces apoptosis in the substantia nigra in vivo and dopaminergic cells in vitro. Exp. Neurol. 177, 453-460. doi: 10.1006/exnr.2002.8012

Trevino-Villarreal, J. H., Vera-Cabrera, L., Valero-Guillén, P. L., and Salinas-Carmona, M. C. (2012). Nocardia brasiliensis cell wall lipids modulate macrophage and dendritic responses that favor development of experimental actinomycetoma in BALB/c mice. Infect. Immun. 80, 3587-3601. doi: 10.1128/IAI.00446-12

Vera-Cabrera, L., Ortiz-Lopez, R., Elizondo-Gonzalez, R., and Ocampo-Candiani, J. (2013). Complete genome sequence analysis of Nocardia brasiliensis HUJEG-1 reveals a saprobic lifestyle and the genes needed for human pathogenesis. PLoS ONE 8:e65425. doi: 10.1371/journal.pone.0065425

Verschoor, J. A., Baird, M. S., and Grooten, J. (2012). Towards understanding the functional diversity of cell wall mycolic acids of Mycobacterium tuberculosis. Prog. Lipid Res. 51, 325-339. doi: 10.1016/j.plipres.2012.05.002

Viguier, C., Arora, S., Gilmartin, N., Welbeck, K., and O’kennedy, R. (2009). Mastitis detection. Current trends and future perspectives. Trends Biotechnol. 27, 486-493. doi: 10.1016/j.tibtech.2009.05.004

Wang, C., and Youle, R. J. (2009). The role of mitochondria in apoptosis. Annu. Rev. Genet. 43, 95. doi: 10.1146/annurev-genet-102108-134850

Wilson, J. W. (2012). Nocardiosis: updates and clinical overview. Mayo Clin. Proc. 87, 403-407. doi: 10.1016/j.mayocp.2011.11.016

Wu, G., Nie, L., and Zhang, W. (2006). Predicted highly expressed genes in Nocardia farcinica and the implication for its primary metabolism and nocardial virulence. Antonie Van Leeuwenhoek 89, 135-146. doi: 10.1007/s10482-005-9016-Z

Xu, Z. Y., Zheng, M. X., Zhang, Y., Cui, X. Z., Yang, S. S., Liu, R. L., et al. (2016). The effect of the mitochondrial permeability transition pore on apoptosis in Eimeria tenella host cells. Poult. Sci. 95, 2405-2413. doi: 10.3382/ps/ pew198

Yang, S. S., Zheng, M. X., Xu, H. C., Cui, X. Z., Zhang, Y., Zhao, W. L., et al. (2015). The effect of mitochondrial ATP-sensitive potassium channels on apoptosis of chick embryo cecal cells by Eimeria tenella. Res. Vet. Sci. 99, 188-195. doi: 10.1016/j.rvsc.2015.02.002

Zhang, F., and Xie, J. P. (2011). Mammalian cell entry gene family of Mycobacterium tuberculosis. Mol. Cell. Biochem. 352, 1-10. doi: 10.1007/s11010-011-0733-5

Zoropogui, A., Pujic, P., Normand, P., Barbe, V., Belli, P., Graindorge, A., et al. (2013). The Nocardia cyriacigeorgica GUH-2 genome shows ongoing adaptation of an environmental Actinobacteria to a pathogen's lifestyle. BMC Genomics 14:286. doi: 10.1186/1471-2164-14-286

Conflict of Interest Statement: The authors declare that the research was conducted in the absence of any commercial or financial relationships that could be construed as a potential conflict of interest.

Copyright (c) 2017 Chen, Liu, Zhang, Gu, Liu, Shahid, Gao, Ali and Han. This is an open-access article distributed under the terms of the Creative Commons Attribution License (CC BY). The use, distribution or reproduction in other forums is permitted, provided the original author(s) or licensor are credited and that the original publication in this journal is cited, in accordance with accepted academic practice. No use, distribution or reproduction is permitted which does not comply with these terms. 